\title{
Determination of the Separation Densities to Achieve the Greatest Yield of the Concentrate of Hard-Cleaning Coals
}

\author{
Vladimir Udovitsky ${ }^{1, *}$, and Vladimir Kandinsky ${ }^{1}$ \\ ${ }^{1}$ T.F. Gorbachev Kuzbass State Technical University, Department of mineral resources processing, \\ 650000 Kemerovo, 28 Vesennya st., Russian Federation
}

\begin{abstract}
A variant of application of Reinhardt's theorem for determination of separation densities at which it is possible to obtain the maximum ultimate yield of gravity concentrate with a particle size of 0.5 $100 \mathrm{~mm}$ at a given ash content obtained from hard-cleaning coals of two machine classes $13-100$ and $0.5-13 \mathrm{~mm}$ is considered. The separation densities are found using the washability curves built in Microsoft Excel. The results of the theoretical and practical balances calculated for the found separation densities are compared. It has been established that for hard-cleaning coals in the practical balance, it is not always possible to obtain the ash content of the ultimate concentrate specified in the theoretical balance even with a decrease in the separation densities to a minimum value.
\end{abstract}

\section{Introduction}

In different years, many authors have sought to develop mathematical models for calculating the theoretical and practical balances of the washing products, which make it possible to achieve the greatest yield of the concentrate with the planned ash, both with and without the use of washability curves [1-6].

The theoretical balance of washing products is designed to determine theoretically possible process parameters of washing products. The theoretical balance of washing products is determined using washability curves built on the results of float-and-sink analysis of coal. The analysis is carried out and the curves are prepared in accordance with GOST 4790-93 (ISO 7936-92).

In our case, in the theoretical balance, in order to determine the separation densities at which the maximum ultimate yield of the concentrate at the preset ash content can be obtained, the well-known Reinhardt's theorem based on the use of washability curves is applied $[7,8]$.

The washability curves are built in Microsoft Excel. The initial data for the graphical representation of the curves are represented by the granulometric and fractional compositions of the charge, consisting of hard-cleaning coals from seams 89 and 90 in

* Corresponding author: uvi@kuzstu.ru 
50:50 ratios. The granulometric and fractional compositions of coals are taken from the study [9].

The practical balance of washing products is calculated for the same separation densities as in the theoretical balance according to the technological scheme consisting of preliminary screening operations; crushing of large class over $100 \mathrm{~mm}$; heavy-media separation of class 13-100 $\mathrm{mm}$ in the SKVP separator, followed by dewatering of concentrate, middlings and rock on resonance screens; deslurring of class $0-13 \mathrm{~mm}$ prior to jigging in BATAC jigger, and the concentrate jig in centrifuges. Mathematical models of gravitational preparation processes for heavy-media separators SKVP and jigging machines BATAC $\AA$ are taken from publications [10-13]. Models are based on the use of separation efficiency indicators for heavy-media units $\mathrm{E}_{\mathrm{p}}$ (I'Ecart probable moyen) [14]; for jiggers - I (Imperfection) $[15,16]$.

\section{Materials and Methods}

Drawing up the theoretical balance using the Reinhardt theorem: "If, when separately washing several coals, it is required to obtain an ultimate concentrate with a given ash content, the maximum ultimate yield of the concentrate with the total specified ash content will be obtained with the same average ash content of the elementary separation layers."

Making the washability curves. Based on the data from Tables 1-3, the washability curves were prepared by machine classes (Figures 1-3).

Making the curve of float fractions $\beta$ showing the relationship between the yield of float fractions and their ash content: the ultimate yields of the float fractions are plotted on the ordinate axis from top to bottom; the lines of the fraction yields (demarcation lines) are drawn from the obtained points parallel to the axis of abscissae. The ultimate ash content of the floating fractions is plotted sequentially on these lines. The points obtained from the intersection of the lines are connected by a smooth curve.

To plot the curve of the sink fractions $\theta$ showing the relationship between the yield of sink fractions and their ash content, the ultimate yields of the sink fractions are plotted on the ordinate (right) axis from bottom to top. The ultimate ash content of the sink fractions is plotted sequentially on the lines of the fraction yield. The points obtained from the intersection of the lines are connected by a smooth curve.

Making the curve of elementary fractions $\lambda$ showing the relationship between the yield of the float fractions and the ash content of the elementary layers: the ash content of the individual fractions is sequentially plotted on the lines of yield of the corresponding fractions, and from the points obtained, segments parallel to the ordinate are drawn within each fraction. Through the middle of the segments, a smooth curve is drawn so that the areas of the triangles cut off by the curve within each fraction are equal

The density curve $\rho$ showing the relationship between the yield of the float fractions and their density is drawn through the intersection points of the demarcation lines with the fractional density lines.

Determination of separation densities at which the greatest ultimate yield of concentrate can be achieved.

First, we plot the washability curves for the machine grade $0.5-100 \mathrm{~mm}$. The specified ash content of the ultimate concentrate of class $0.5-100 \mathrm{~mm}$ (in this example $9.5 \%$ ) is plotted on the lower abscissa axis (Fig. 1), and the perpendicular is drawn to the intersection with curve $\beta$. Through the intersection point, a horizontal line is drawn that intersects the ordinate axis and the curve $\lambda$. The segment $[\mathrm{a}, \mathrm{b}]$ is obtained, the projection of which on the abscissa axis characterizes the ash content of the elementary fraction. 
Table 1. The data for making the washability curves, class $0.5-100 \mathrm{~mm}$.

\begin{tabular}{|c|c|c|c|c|c|c|}
\hline \multirow{2}{*}{$\begin{array}{c}\text { Density of } \\
\text { fractions, } \\
\text { g/cm } \mathbf{c m}^{3}\end{array}$} & \multirow{2}{*}{$\begin{array}{c}\text { Yield, } \\
\%\end{array}$} & \multirow{2}{*}{$\begin{array}{c}\text { Ash } \\
\text { content, } \\
\% \\
\end{array}$} & \multicolumn{2}{|c|}{ Floaters } & \multicolumn{2}{|c|}{ Sinkers } \\
\hline & & & Yield, \% & Ash content, \% & Yield, \% & Ash content, $\%$ \\
\hline$<1,3$ & 34,68 & 8,24 & 34,68 & 8,24 & 81,04 & 24,99 \\
\hline $1,3-1,4$ & 19,82 & 18,75 & 54,50 & 12,06 & 46,36 & 37,52 \\
\hline $1,4-1,5$ & 9,61 & 27,26 & 64,11 & 14,34 & 26,54 & 51,53 \\
\hline $1,5-1,6$ & 3,74 & 35,94 & 67,85 & 15,53 & 16,93 & 65,31 \\
\hline $1,6-1,8$ & 3,08 & 48,66 & 70,92 & 16,97 & 13,19 & 73,64 \\
\hline$>1,8$ & 10,11 & 81,24 & 81,04 & 24,99 & 10,11 & 81,24 \\
\hline Total & 81,04 & 24,99 & & & & \\
\hline
\end{tabular}

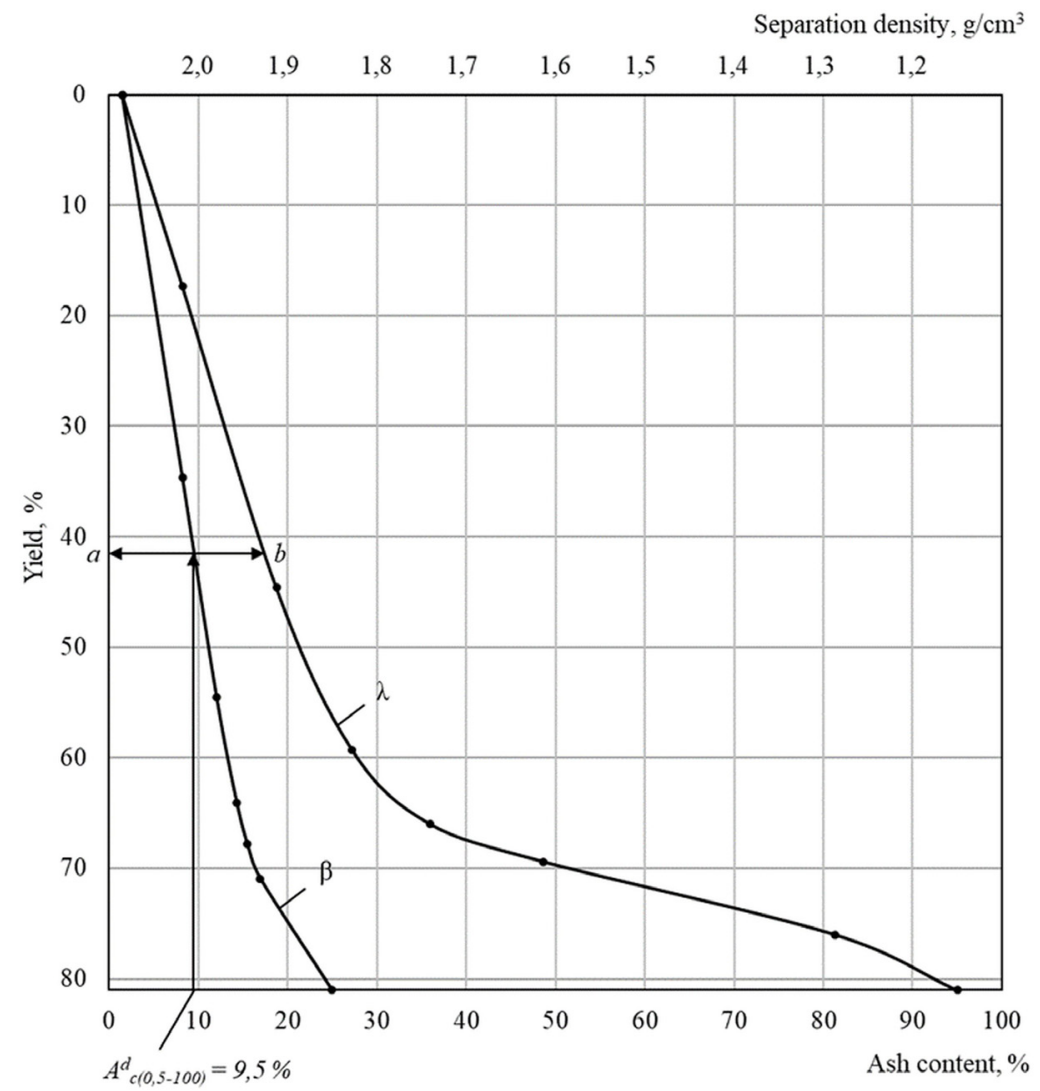

Figure 1. Washability curves of class $0.5-100 \mathrm{~mm}$.

Determination of the separation density for concentrate of class 13-100 $\mathrm{mm}$. Lay the value of section [a, b] on the abscissa axis (Fig. 2) and draw the perpendicular to the intersection with curve $\lambda$. Through the intersection point, draw a horizontal line that intersects the ordinate and curves $\theta$ and $\beta$. The yield and the ash content of the concentrate are $\gamma_{k}=9.5 \%, A^{d}{ }_{k}=13.0 \%$, obtained at the separation density $\rho_{\kappa}=1.34 \mathrm{~g} / \mathrm{cm} 3$. The found values are placed in the corresponding lines of columns 2 and 3 of Table. 4. 
Table 2. The data for making the washability curves, class $13-100 \mathrm{~mm}$.

\begin{tabular}{|c|c|c|c|c|c|c|}
\hline \multirow{2}{*}{$\begin{array}{l}\text { Density of } \\
\text { fractions, } \\
{\mathrm{g} / \mathrm{cm}^{3}}^{3}\end{array}$} & \multirow{2}{*}{$\begin{array}{c}\text { Yield, } \\
\%\end{array}$} & \multirow{2}{*}{$\begin{array}{c}\text { Ash } \\
\text { content, } \\
\%\end{array}$} & \multicolumn{2}{|c|}{ Floaters } & \multicolumn{2}{|c|}{ Sinkers } \\
\hline & & & Yield, \% & Ash content, \% & Yield, \% & Ash content, $\%$ \\
\hline$<1,3$ & 6,23 & 10,90 & 6,23 & 10,90 & 27,71 & 32,28 \\
\hline $1,3-1,4$ & 9,03 & 18,73 & 15,26 & 15,53 & 21,48 & 38,48 \\
\hline $1,4-1,5$ & 4,61 & 27,35 & 19,87 & 18,27 & 12,44 & 52,81 \\
\hline $1,5-1,6$ & 1,69 & 36,06 & 21,57 & 19,67 & 7,83 & 67,80 \\
\hline $1,6-1,8$ & 0,90 & 48,84 & 22,47 & 20,85 & 6,14 & 76,56 \\
\hline$>1,8$ & 5,24 & 81,35 & 27,71 & 32,28 & 5,24 & 81,35 \\
\hline Total & 27,71 & 32,28 & \multicolumn{4}{|c|}{ Washability very difficult, $T=32,1 \%$} \\
\hline
\end{tabular}

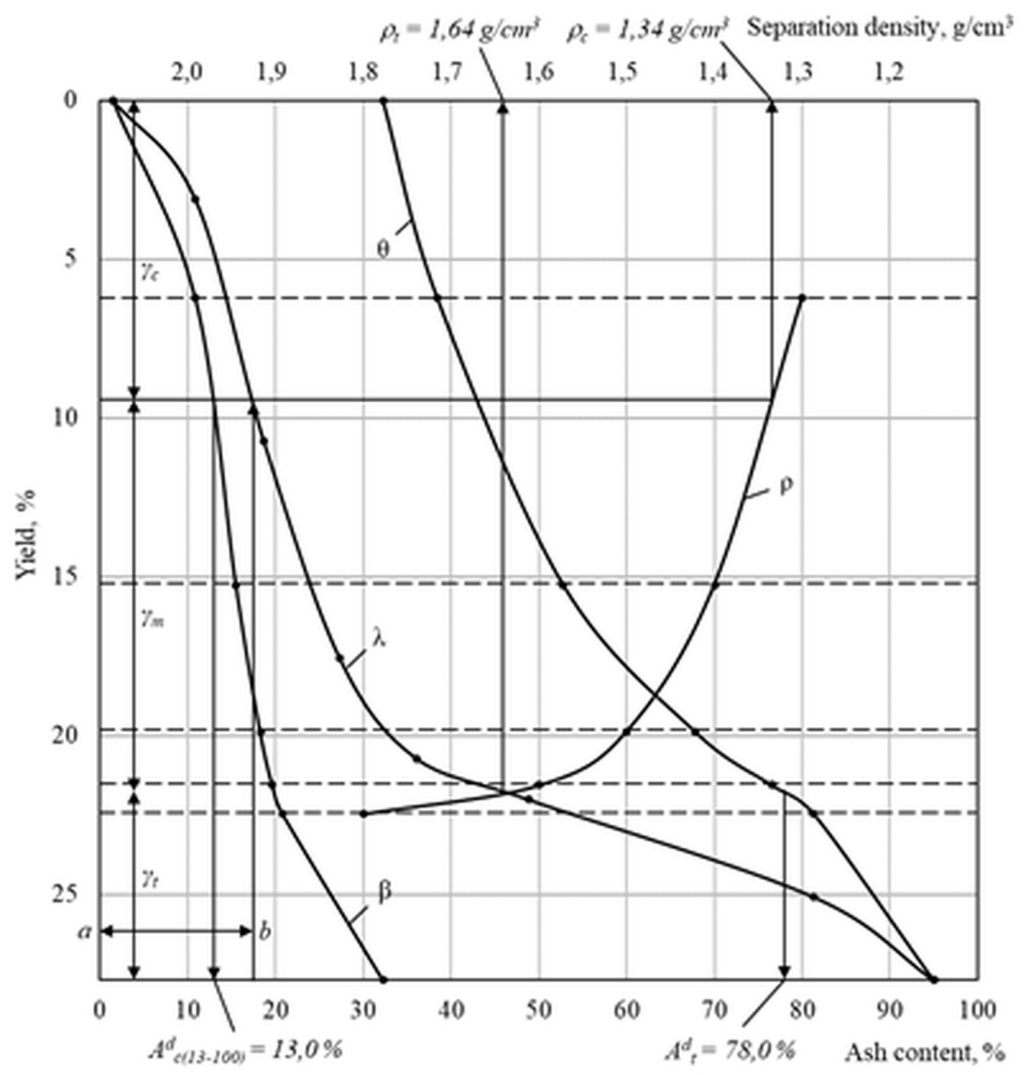

Figure 2. Washability curves of machine class $13-100 \mathrm{~mm}$

Determination of the separation density for concentrate of class $0.5-13 \mathrm{~mm}$. Lay the value of section [a, b] on the abscissa axis (Fig. 3) and draw the perpendicular to the intersection with curve $\lambda$. Through the intersection point, draw a horizontal line that intersects the ordinate and curves $\theta$ and $\beta$. The yield and the ash content of the concentrate class $0.5-13$ are respectively $32.0 \%$ and $8.5 \%$; the above values can be obtained at the separation density $1.33 \mathrm{~g} / \mathrm{cm} 3$. The found values are placed in the corresponding lines of columns 2 and 3 of Table. 4. 
Table 3. The data for making the washability curves, class $0.5-13 \mathrm{~mm}$

\begin{tabular}{|c|c|c|c|c|c|c|}
\hline $\begin{array}{c}\text { Density of } \\
\text { fractions, } \\
\text { g/cm }\end{array}$ & \multirow{2}{*}{$\begin{array}{c}\text { Yield, } \\
\text { \% }\end{array}$} & \multirow{2}{*}{$\begin{array}{c}\text { Ash } \\
\text { content, } \\
\mathbf{\%}\end{array}$} & \multicolumn{2}{|c|}{ Floaters } & \multicolumn{2}{c|}{ Sinkers } \\
\cline { 4 - 7 } & & Yield, \% & Ash content, \% & Yield, \% & Ash content, \% \\
\hline$<1,3$ & 28,45 & 7,66 & 28,45 & 7,66 & 53,33 & 21,20 \\
\hline $1,3-1,4$ & 10,79 & 18,76 & 39,23 & 10,71 & 24,89 & 36,69 \\
\hline $1,4-1,5$ & 5,00 & 27,18 & 44,24 & 12,57 & 14,10 & 50,40 \\
\hline $1,5-1,6$ & 2,05 & 35,83 & 46,28 & 13,60 & 9,10 & 63,17 \\
\hline $1,6-1,8$ & 2,17 & 48,58 & 48,46 & 15,17 & 7,05 & 71,10 \\
\hline$>1,8$ & 4,88 & 81,13 & 53,33 & 21,20 & 4,88 & 81,13 \\
\hline Total & 53,33 & 21,20 & \multicolumn{3}{|c|}{ Washability very difficult, $T=19,0 \%$} \\
\hline
\end{tabular}

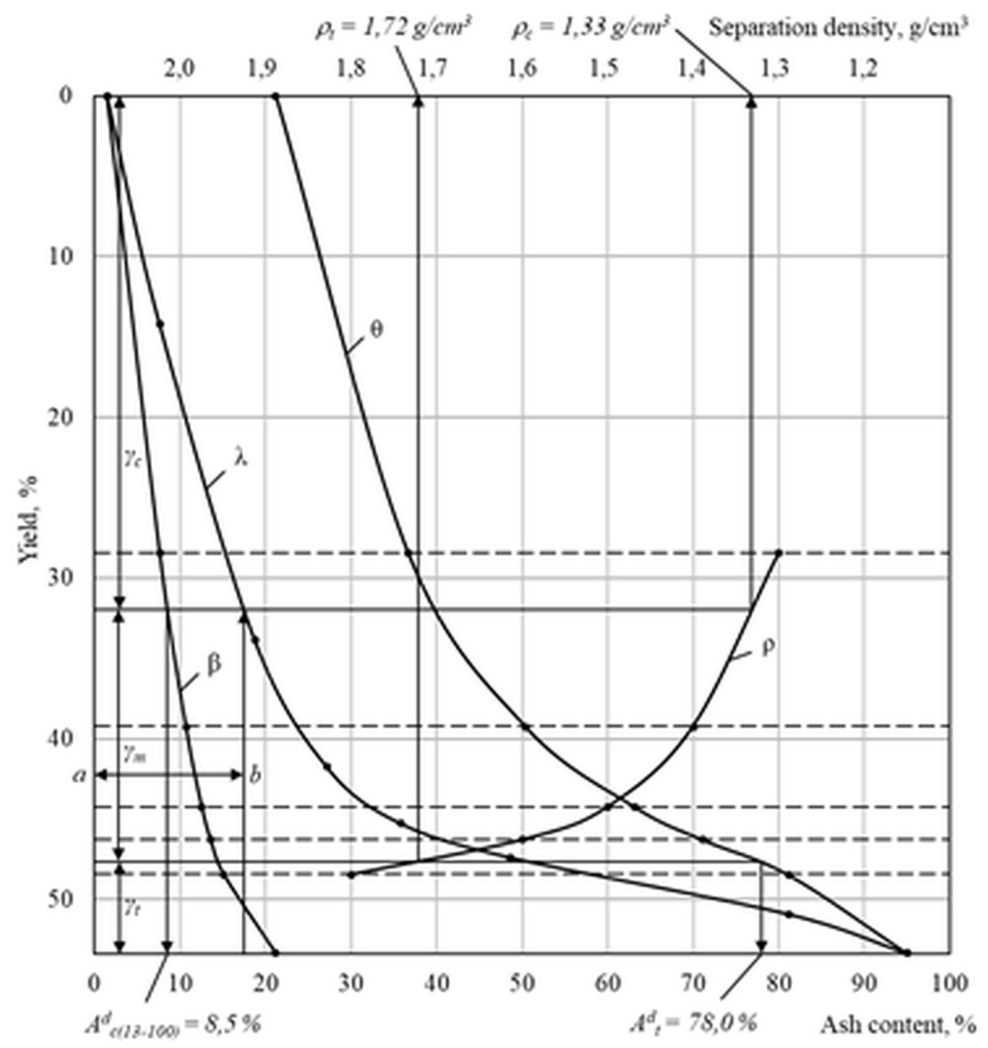

Figure 3. Washability curves of machine class $0.5-13 \mathrm{~mm}$

\section{Results and Discussion}

The theoretical balance of washing products

Calculation of yield and ash content of rejects and middlings, class 13-100 mm

Let us assume the ash content* of rock $A^{d}{ }_{n}=78.0 \%$. Adp $=78.0 \%$. The yield of rock $\gamma_{n}=6.0 \%$ corresponds to this ash content at the separation density $\rho_{n}=1.64 \mathrm{~g} / \mathrm{cm} 3$.

The yield and ash content of the middlings are determined from the balance equations:

$$
\gamma_{n n}=27.71-9,5-6,0=12.21 \% \text {, }
$$




$$
A^{d}{ }_{n n}=(27.71 \cdot 32.28-9.5 \cdot 13.0-6.0 \cdot 78.0) / 12.21=24.81 \%,
$$

Where $27.71 \%$ - yield of class $13-100 \mathrm{~mm} ; 32.28 \%$ - ash content of the same class; $9.5 \%$ and $13.0 \%$ - yield and ash content of the concentrate; $6.0 \%$ and $78.0 \%$ - yield and ash content of the rock.

The found values of yield and ash content of rock and middlings, machine class 13-100 $\mathrm{mm}$, are entered in the lines of columns 2 and 3 of Table. 4.

Calculation of yield and ash content of rejects and middlings, class $0.5-13 \mathrm{~mm}$

Let us assume the ash content of rock $A^{d}{ }_{n}=78.0 \%$. Adp $=78.0 \%$. The yield of rock $\gamma_{n}=6.3 \%$ corresponds to this ash content at the separation density $\rho_{n}=1.72 \mathrm{~g} / \mathrm{cm} 3$.

The yield and ash content of the middlings are determined from the balance equations:

$$
\begin{gathered}
\gamma_{n n}=53.33-32.0-6.3=15.03 \%, \\
A^{d}{ }_{n n}=(53.33 \cdot 21.20-32.0 \cdot 8.5-6.3 \cdot 78.0) / 15.03=24.45 \% .
\end{gathered}
$$

The found values of yield and ash content of rock and middlings, machine class 0.5-13 mm, are entered in the corresponding lines of columns 2 and 3 of Table. 4.

The practical balance of washing products

In accordance with the conditions specified in Section 1 and the technological scheme of coal preparation, the practical balance of washing products was calculated for the specified separation densities using the computer program Si_Ig_Kp.pas developed by the authors.

Mathematical models of the processes and the technological scheme of coal preparation implemented in the program take into account the effectiveness of preparatory, basic and auxiliary processes of coal preparation; additional slurry formation.

\begin{tabular}{|c|c|c|c|c|}
\hline \multirow{2}{*}{ Washing products } & \multicolumn{2}{|c|}{ Theoretical balance } & \multicolumn{2}{|c|}{ Practical balance } \\
\hline & Yield, \% & Ash, \% & Yield, \% & Ash, \% \\
\hline 1 & 2 & 3 & 4 & 5 \\
\hline Concentrate, class, mm & $\begin{array}{c}9.5 \\
32.0\end{array}$ & $\begin{array}{c}13.0 \\
8.5 \\
\end{array}$ & $\begin{array}{l}11.03 \\
24.89\end{array}$ & $\begin{array}{l}13.65 \\
10.00\end{array}$ \\
\hline Total concentrate & 41.5 & 9.53 & 35.91 & 11.12 \\
\hline Middlings, class, mm & $\begin{array}{l}12.21 \\
15.03\end{array}$ & $\begin{array}{l}24.81 \\
24.45\end{array}$ & $\begin{array}{l}12.07 \\
13.74\end{array}$ & $\begin{array}{l}24.36 \\
23.22\end{array}$ \\
\hline Total middlings & 27.24 & 24.61 & 25.81 & 23.75 \\
\hline Rejects, class, mm & $\begin{array}{l}6.0 \\
6.3\end{array}$ & $\begin{array}{l}78.0 \\
78.0\end{array}$ & $\begin{array}{l}6.28 \\
5.06\end{array}$ & $\begin{array}{l}75.96 \\
72.17\end{array}$ \\
\hline Total rejects & 12.3 & 78.0 & 11.34 & 74.27 \\
\hline Total for class $0.5-100 \mathrm{~mm}$ & 81.04 & 24.99 & 73.06 & 25.38 \\
\hline
\end{tabular}

The results of the calculation are presented in columns 4 and 5 of Table 4 .

Table 4. The theoretical and practical balances of gravity washing products.

\section{Conclusions}

The following has been established with the help of computational experiments for hardcleaning coal of seams 89 and 90 :

1. At separation densities (for class of 13-100 mm - $1.34 \mathrm{~g} / \mathrm{cm} 3$ and for 1. 5-13 mm$1.33 \mathrm{~g} / \mathrm{cm} 3$ ) found by washability curves, the maximum yield of the ultimate concentrate in the theoretical balance is $41.5 \%$ for a given ash content of $9.5 \%$. Similar indicators for the ultimate concentrate in the practical balance are equal, respectively $35.9 \%$ and $11.1 \%$; 
2. The planned ash content of the ultimate concentrate of $9.5 \%$ in the practical balance cannot be achieved even at the lowest separation density of $1.3 \mathrm{~g} / \mathrm{cm} 3$ in classes of 13-100 and $0.5-13 \mathrm{~mm}$. In the practical balance calculated using the program Si_Ig_Kp.pas, the ash content of the ultimate concentrate for this separation density is $10.3 \%$ at the maximum yield of $29.0 \%$.

3. The difference between the theoretical and practical balances is explained by the fact that the technological indicators of coal preparation in the practical balance depend on the scheme of preparation, efficiency indicators of preparatory, main and auxiliary washing processes, and additional sludge formation. The above indicators are not considered in Reinhardt's theorem and theoretical balance.

\section{References}

1. Daniel D. McCracken, William S. Dorn, (John Wiley and Sons, Inc., New York, 1965)

2. S. Smirnov, Aacher Blatter, 5 (1968)

3. O. Radek, Uhli, 7 (1971)

4. G. Sanders, D. Ziaja, J. Kottmann, Coal Prep. 22 (2002)

5. K.K. Humphreys, L.W. Leonard, I.A. Buttermore, Coal Age, 7 (1972)

6. V. Chudovitsky, XX International Mineral Processing Congress (Aachen, Germany, 1997)

7. K. Reinhardt, Glückauf, 47, 6 (1911)

8. K. Reinhardt, Glückauf, 62 (1926)

9. V. Chudovitsky, Regional APCOM'97 Symposium: The Moscow State Mining University (Publishing Center Moscow, Russia, 1997)

10. J. Winckler, G. Mustafi, Mining Challenges of the 21st Century (APH Publishing Corp., New Delhi, 2000)

11. V. Udovitsky, V. Kandinsky, A. Begunov, E3S Web of Conferences, 15 (2017)

12. V. Kandinsky, I. Korolev, V. Udovitsky, Key Engineering Materials, 743 (2017)

13. I. Korolev, V. Udovitsky, XVIII International Coal Preparation Congress (Saint Petersburg, Russia, 2016)

14. K. Tromp, Glückauf, 73 (1937)

15. A. Terra, Revue de l'industrie minerale 446 (1939)

16. A. Terra, R.I.M., 626 (1955) 